\title{
Rivalry in Price and VAriety among SUPERMARKET RETAILERS
}

\author{
Timothy J. Richards AND STEPHEN F. HAMILton
}

\begin{abstract}
Recent theoretical models of retail competition suggest that product heterogeneity is critical to retail price and variety strategies. This article provides empirical evidence on supermarket retailers' price and variety strategies using a nested constant elasticity of substitution (NCES) modeling framework. The model is estimated using chain-level scanner data for four major grocery chains in a large, urban West Coast market. The results show that retailers compete for market share using both price and variety. While they all tend to follow moderately cooperative pricing strategies, the extent to which they follow cooperative strategies in variety is less homogeneous.
\end{abstract}

Key words: game theory, nested CES, price competition, retailing, variety.

Between 1980 and 1999, the average number of products stocked in the U.S. supermarkets increased threefold from 14,145 to 49,225 (Food Marketing Institute 2004). ${ }^{1}$ It is not clear whether this trend reflects a more competitive retail industry, or an industry that supports higher margins through various forms of nonprice competition. Certainly, there is some cause for concern, as growth in the average number of products stocked in the supermarkets increases retail fixed costs and limits the ability of smaller food retailers to enter the market. However, to the extent that greater product variety creates better matches between consumers and brands, growth in the number of products tends to increase consumer spending in supermarkets, and this raises the return to retailers from attracting customers to their stores. A greater number of products can thus intensify retail price competition between supermarkets and produce similar effects as potential competition from entrants. Does product variety selection play a strategic role for supermarkets? And, if so, what is the effect

\footnotetext{
Timothy J. Richards is Power Professor of Agribusiness at the Morrison School of Agribusiness and Resource Management, Arizona State University and Stephen F. Hamilton is associate professor at the Orfalea College of Business, California Polytechnic State University.

The authors wish to acknowledge helpful comments from two anonymous reviewers, Azzeddine Azzam, Konstantinos Giannakas, Kyle Stiegert, and the participants in the Food Systems Research Group (FSRG) Conference, June 2005, Madison, Wisconsin Funding from FSRG grant number 2004-A2 is gratefully acknowledged.

${ }^{1}$ In the year 2000, 16,390 new flavors, colors, or varieties of products were introduced, compared with 2,689 in 1980.
}

of product variety choices on retail price competition?

This article describes an empirical framework that we use to test the nature of price and variety competition among multiproduct retailers. Unlike previous empirical work that considers only retail competition in prices, a structural approach allows us to consider retail competition as arising jointly through the selection of prices and product variety. Specifically, the model nests consumer demand at both the firm (or chain) and the product level in a single utility-maximization problem that explicitly accounts for the endogeneity of price and variety strategies.

A number of studies consider treat grocery retailers as local monopolists (Slade 1995; Besanko, Gupta, and Jain 1998; Dhar et al. 2003). This assumption is based on the evidence that consumers base their storeselection decisions on attributes unrelated to market prices, such as location, cleanliness, service, and product variety (Walters and McKenzie 1988). That is, retailers may use these various forms of nonprice competition to differentiate themselves into local monopoly markets. Moreover, it is also the case that shoppers generally find it easier to compare prices across products within a store than to compare prices of common products across retail stores (Slade 1995), and this also tends to promote localized brand competition. ${ }^{2}$ Under this view, providing product variety would serve as an

\footnotetext{
2 Throughout this article, we use the terms "store," "chain," and "firm" interchangably as our interest is in firm-level strategies and
} 
instrument for retailers to extract multiproduct monopoly rents from consumers through "portfolio" pricing.

But it is also possible that greater retail product variety stimulates price competition. For example, if consumers base their storeselection decisions on retailer location, then providing more varieties can spread consumer transportation cost over a greater number of goods, effectively reducing the extent of nonprice retailer differentiation at the individual product level where pricing occurs. Indeed, a cursory examination of the recent financial performance of U.S. supermarket chains reveals that the rate of turnover in grocery store ownership appears to better approximate what we might expect to see under perfect competition. It is well known, moreover, that supermarket managers seek to maintain the competitiveness of their stores across entire categories of goods, and accordingly set prices in a manner that takes rival retail prices into account (McLaughlin, et al. 1999). This idea that retailers are not impervious to competitive market forces is consistent with an emerging body of evidence which suggests that the local monopoly view of retailing is not strictly true (Chintagunta 2002; Chintagunta, Dube, and Singh 2002; Richards and Patterson 2005a; 2005b).

In this article, we take the view that consumers make two discrete decisions before purchasing a product: (1) which retailer to visit; and (2) which products to buy from a particular retailer. Shopping in this framework originates from a need. The consumer runs out of products $x, y$, and $z$, and then decides how to satisfy this need by choosing from among firms $\mathrm{i}, \mathrm{j}$, and $k$. The element of consumer store choice tends to stimulate intense price and nonprice competition among retailers. However, once consumers arrive at their store choices, retailers exercise local monopoly power. Because retail price discrimination is generally not possible between consumers who are shopping for brands and consumers who are shopping for stores, retailers use prices and other means, in-

our data are aggregated over all individual stores within each chain. Because our data do not describe the many potential dimensions of nonprice competition among supermarket retailers (location, cleanliness, advertising, etc.), we focus our objectives on a discussion of variety. Other factors are assumed to be included in chainlevel fixed-effects estimates. It is important to note that we assume prices are set at the chain, rather than individual store level. Given that our data are aggregated to the firm level and we observe many products for which the price stays at a recognizable price point, for example, $\$ 1.79$ per pound, for several weeks, it is clear that this price is set for every store in the entire chain. Personal communication with store managers for two of the sample firms supports this empirical evidence. cluding variety provision, to forge a compromise between these two roles.

We test the model using weekly sales data within the fresh fruit category in supermarkets in the greater Los Angeles (LA) area. Fresh fruit sold at LA supermarkets is an ideal product category to study variety decisions for several reasons. First, fresh fruit represents a unique opportunity to study competition that is not driven by manufacturer promotion programs, category management, or obligations created under slotting or pay-to-stay fee agreements. Second, LA represents an ideal case study because there are a small number of retailers who dominate the retail market, each retailer follows a price-promotional strategy (HI-LO) as opposed to an every-day-lowprice (EDLP) strategy, and Wal-Mart, which does not participate in any national scannerdata syndication services, does not sell groceries in the area. ${ }^{3}$ Third, fresh fruit is an unbranded commodity (or else symmetrically branded across retailers), and not sold under independent retailer private labels. Fourth, fresh fruit at LA supermarkets is priced on a chain-wide basis for each retailer, so that fresh fruit prices do not differ among stores within each retail chain. Finally, survey research finds fresh fruit and vegetable quality and availability to be among the most important considerations consumers take into account in choosing a supermarket. ${ }^{4}$ This allows for a relatively straightforward empirical examination of whether grocery retailers compete in prices, variety, both prices and variety, or are insulated entirely from either form of competition.

The remainder of the article is organized as follows. The next section reviews the background literature. The third section delineates the empirical model. The fourth section discusses data and estimation methods, and the fifth section presents the results.

\section{Background}

Dixit and Stiglitz (1977) and Spence (1976) were among the first to develop formal models of product variety and price. The models follow

\footnotetext{
${ }^{3}$ A HI-LO business model is one in which the retailer maintains a relatively high shelf price, but periodically offers significant discounts. EDLP retailers, on the other hand, maintain shelf prices that are as low as possible and rarely offer specials or discounts. Wal-Mart is an example of the latter, while Albertsons is an example of the former.

${ }^{4}$ Eighty-five percent of consumers regard high-quality fruits and vegetables to be "very important" to their choice of store (Food Marketing Institute 2004), and only cleanliness rates higher among store attributes.
} 
along traditional lines of monopolistic competition in the sense that product proliferation emerges as an equilibrium condition through tension between the cost of developing new products and the role of new products in increasing total product demand through portfolio effects. Each product is produced by an individual firm, and firms (products) enter the industry until demand for brands is no longer sufficient to recover entry costs. More recently, Raubitschek (1987) extends the constant elasticity of substitution (CES) model of Dixit and Stiglitz by replacing the equilibrium condition with a two-stage optimization process in which a centralized manager for each firm selects the number of brands to offer in the first stage, and then each brand is priced independently by individual brand managers in the second stage. This approach ignores the coordination of pricing decisions across retail products.

Anderson and de Palma (1992) make the useful distinction that differentiation often results in the selection of only one retail store and only one product, for example, a shoe store. They develop a model of price and variety competition in which consumers select among stores, and then products within stores, according to a nested logit framework. In equilibrium, they argue, greater heterogeneity among retailers leads to less variety, while greater heterogeneity among products within each store promotes variety. However, it is well understood that the nested logit model, while more general than a simple logit in the sense that it allows for store and product heterogeneity through extreme-value scale parameters, leads to unrealistic substitution patterns among products within each nest. ${ }^{5}$ The nested logit approach also implies that a corner solution must exist at each choice level. de Palma et al. (1994) apply this framework to explain spatial competition among video store owners in prices and variety, but do not formally test the implications of the theory. ${ }^{6}$ Watson (2004) formally tests a variety and price game of this form under circumstances of endogenous location choices and finds that variety is a concave function of the number of local competitors.

\footnotetext{
${ }^{5}$ The basic problem with the logit model is the independence of irrelevant alternatives (iia) property, which means that "...the ratio of the probabilities for any two alternatives is independent of the existence and attributes of any other alternative..." (Brownstone and Train 1999, p. 110). While the nested logit model avoids the iia property between different nests, the model is still subject to this criticism with respect to the choice of products from within a particular nest.

${ }^{6}$ The authors address a specific example, but do not formally test the hypotheses.
}

Strategic product proliferation is important in a nonspatial sense as well. Brander and Eaton (1984) develop a model of strategic preemption in which producers of substitutable products are likely to monopolize a particular market segment in order to deter entry. Hamilton (2003) synthesizes these two branches of the modeling literature by combining a discrete store-choice model with a model of within-store product choice. This model allows for heterogeneity among retail firms as well as heterogeneity among brands, and, unlike Anderson and de Palma, considers continuous quantity choices and an outside option. The outcome is that greater retailer heterogeneity leads to a smaller provision of product variety, whereas greater heterogeneity among products sold by each firm has an ambiguous effect on variety. The reason for this is that greater product heterogeneity increases retail margins, which increases the return to new product introductions, but higher prices also dampen retail sales per brand by facilitating substitution to the outside good. The present article provides an empirical test of these theoretical predictions.

Few empirical studies have examined product variety decisions in retail markets. Indeed, virtually all previous empirical research on the competitive aspects of product variety is directed at the manufacturing level, where "product lines" are typically comprised of a small set of related brands and competitors are few (Bayus and Putsis 1999; Kadiyali, Vilcassim, and Chintagunta, 1996, 1999; Dobson and Kalish 1988; Oren, Smith, and Wilson 1984). Roberts and Samuelson (1988) design and estimate a repeated two-period noncooperative oligopoly model among the U.S. cigarette manufacturers in which the number of brands is a key determinant of demand, but the number of varieties to offer is not treated as a strategic choice variable. Models of productline competition in the empirical literature are commonly specified at the level of individual brands using product-level conduct parameters, while the proliferation decision, itself, is either treated as exogenous (Kadiyali, Vilcassim, and Chintagunta 1996; 1999) or without any reference to a structural model of competition (Bayus and Putsis). Kadiyali, Vilcassim, and Chintagunta (1999) demonstrate that yogurt producers are able to acquire market power through the portfolio effect of offering a greater array of products, as a larger range of products effectively reduces a measure of the elasticity of demand over their 
whole product line. Draganska and Jain (2005) recognize the strategic importance of productline length and estimate a model in which the number of varieties offered per product line, as well as the price of the products, are endogenous determinants of retail demand. Draganska and Jain follow Berry (1994), Berry, Levinsohn, and Pakes (1995), and Nevo (2000, 2001) in specifying a logit demand model in which product differentiation is reflected in discrete consumer choices. Although the decision to introduce new products is presumably to attract new customers and/or increase the level of consumption of each customer, both of which can be accomplished by creating better matches between consumers and brands, none of these studies explicitly consider the effect of product differentiation on the nature of retail market competition.

\section{Empirical Model of Variety Competition}

In this section, we develop an econometric model that includes structural equations for: (1) equilibrium prices, (2) equilibrium variety (number of products per firm), and (3) the market share of each firm. Rivalry in either price or variety, in turn, will be largely determined by the degree of differentiation between firms, the extent of product differentiation, differences in marginal cost (wholesale price), and differences in fixed retailing costs. Both the degree of product differentiation and firm differentiation, however, are unobserved to the econometrician. Therefore, the econometric procedure estimates both product and firm differentiation as unknown parameters.

Berry; Berry, Levinsohn, and Pakes; Ackerberg and Rysman (2002), and Nevo (2000, 2001), among others, explicitly account for unobserved product differentiation within a discrete choice framework by treating the extent of differentiation as a latent variable influencing both competition and demand. These studies identify the extent of differentiation in structural supply and demand models in which consumer utility is a function of both observed and unobserved product characteristics. In this context, differentiation is inherent in the product itself, and this necessarily assumes away any further differentiation created by other channel members. Dhar and Cotterill (2003), on the other hand, argue that products purchased in retail supermarkets are differentiated in two dimensions: (1) from other products in the same store according to their embodied attributes, and (2) from similar products sold by other firms on the basis of store characteristics. This implies that a two-stage model of firm and product choice is required to estimate the degree of substitutability both among firms and among products within firms. We adopt a similar conceptual approach here, although we employ fundamentally different methods. ${ }^{7}$

There are several ways to represent the twostage choice process, depending on whether each stage is regarded as discrete (one alternative is chosen) or continuous (several can be chosen). Hanemann (1984) develops an econometric framework based on Deaton and Muellbauer (1980, p. 262) that integrates the discrete choice among brands and the continuous choice of quantity in a single utilitymaximization problem. Vaage (2000) applies this model to Norwegian appliance and power demand, while Chiang (1991), Chintagunta (1993), Richards (2000), and van Oest, Paap, and Franses (2004) consider discrete choices among brands and continuous quantity purchases. Although this approach accommodates discrete / continuous choices in a theoretically consistent way, substitution among brands is driven entirely by their market share and not by fundamental attributes of the choice itself (Nevo 2001) and the price-response parameter in the brand-choice model is constrained to -1.0. Hendel (1999); Kim, Allenby, and Rossi (2002); and Dube (2004) develop more general models of discrete / continuous choice designed to address the problem of "multiple discreteness"-when consumers buy several flavors or varieties of the same basic product on each trip to the store. Although these models are able to accommodate decisions that consist of a mixture of discrete and continuous outcomes, they are more appropriate for household-level data where true corner solutions are observed.

A logical and intuitive alternative to the discrete / continuous approach followed by the studies cited above is a nested logit similar to Anderson and de Palma (1992) de Palma et al. (1994), and Dhar and Cotterill (2003). Although retail grocery shoppers do indeed make a discrete choice among firms, the subsequent choice among products, and the quantities of each, are more appropriately considered to

\footnotetext{
${ }^{7}$ Note that it is not strictly necessary to use any type of twostage approach in order to recover store- and product-substitution elasticities. Villas-Boas (2003) uses a set of brand-store dummy variables in a single-level logit model to accomplish the same task.
} 
be continuous. Consequently, we adopt an approach that offers both a more general treatment of substitutability among products, while retaining the nested decision logic inherent in shoppers' decisions between quality differentiated firms and products within firms - the nested CES (NCES).

The NCES model has several advantages. The model permits general substitution relationships among alternatives, is parsimonious in parameter space, allows for complementarity, has the potential to be flexible, and finally, appears to perform well in empirical application (Brown and Heien 1972; Morey, Breffle, and Greene, 2001). ${ }^{8}$ As our focus is on the choice made during a single shopping occasion, we assume that a household maximizes utility over the products purchased on each shopping trip. Further, we assume that the consumer first chooses among the products she wishes to buy, and then decides from which firm to purchase the entire bundle, based on considerations of both cost and inherent quality of the firm's stores.

Using a two-level NCES specification, the indirect utility function for this problem is written as:

$$
\begin{aligned}
& V\left(p_{\mathrm{ij}}, y\right) \\
& \quad=\left[\sum_{\mathrm{i}=1}^{I}\left[\sum_{\mathrm{j}=1}^{N_{\mathrm{i}}} \hat{p}_{\mathrm{ij}}^{1-\sigma_{\mathrm{i}}}\right]^{(1-\sigma) /\left(1-\sigma_{\mathrm{i}}\right)}\right]^{1 /(1-\sigma)} y
\end{aligned}
$$

where $y$ is income, $\sigma_{\mathrm{i}}$ is the elasticity of substitution among $\mathrm{j}$ products in firm $\mathrm{i}$, and $\sigma$ is the elasticity of substitution among firms (and the outside option) in a given market. Analogous to the nested logit model of price and variety competition of Anderson and de Palma (1992), $\sigma_{i}$ represents the degree of heterogeneity among products within a given firm (prod$u c t$ heterogeneity) and $\sigma$ represents the degree of heterogeneity among firms (retailer heterogeneity). Concavity requires $\sigma_{\mathrm{k}} \in[0, \infty)$ and, to allow for the possibility of corner solutions with respect to firm choice, $\sigma>1$.

For retailers who sell many highly substitutable products with little heterogeneity (e.g., a seller of submarine sandwiches) $\sigma_{\mathrm{i}}$ is likely to be high relative to $\sigma$. However, for retailers

\footnotetext{
${ }^{8}$ Brown and Heien (1972) call their NCES model the S-branch utility tree. This specification was, however, later criticized by Blackorby, Boyce, and Russell (1978) because it implies that preferences are affine homothetic. They reject this attribute of the Sbranch model by specifying a more general Gorman Polar Form model that nests the S-branch as a special case.
}

who sell products meeting many different and diverse needs, like supermarkets, substitution among firms is likely to be greater than within firms. Anderson and de Palma (1992) maintain that retail markets with a high degree of product heterogeneity are likely to have a few firms offering many different products, whereas markets with a high degree of retailer heterogeneity tend to have more firms, but more limited offerings. This is because retailer heterogeneity has no effect on variety provision in their model, and serves only to increase prices. Hamilton (2003) argues that greater retailer heterogeneity raises retail prices, but reduces product variety and stimulates retailer entry by reducing fixed costs of entry. Although the number of firms is not endogenous in our model, we nonetheless are able to test these hypotheses regarding the number of products offered within each retail outlet.

Prices are adjusted for the inherent "quality" of each product and firm in a manner similar to that suggested by Deaton and Muellbauer (1980), and Hanemann (1984) so that corner solutions result from a utilitymaximizing decision. Specifically, we multiply observed prices by a quality index function, $\Psi_{\mathrm{ij}}$. Because the quality index must be strictly positive, we use an exponential form in various quality attributes:

$$
\begin{aligned}
\Psi_{\mathrm{ij}}= & \left(\operatorname { e x p } \left(\beta_{1 \mathrm{ij}}+\beta_{2 \mathrm{ij}} z_{\mathrm{ij}}+\beta_{3 \mathrm{ij}} z p_{\mathrm{ij}}+\beta_{4 \mathrm{ij}} N_{\mathrm{i}}\right.\right. \\
& \left.\left.+\beta_{5 \mathrm{ij}} m_{1}+\beta_{6 \mathrm{ij}} m_{2}+\beta_{7 \mathrm{ij}} m_{3}\right)\right)^{\sigma_{\mathrm{i}} /\left(1-\sigma_{\mathrm{i}}\right)}
\end{aligned}
$$

where $\beta_{1 \mathrm{ij}}$ is an idiosyncratic preference parameter, $z_{\mathrm{ij}}$ is a binary variable indicating whether or not the product was on a promotion during the week, $z p_{\mathrm{ij}}$ is an interaction term between the promotion dummy and shelf price, $N_{\mathrm{i}}$ is the number of products offered by firm i, and $m_{\mathrm{k}}$ are seasonal dummy variables. Multiplying $\Psi$ by the price provides a quality adjusted price so that $\hat{p}_{\mathrm{ij}}=\Psi_{\mathrm{ij}} p_{\mathrm{ij}}$ for each $\mathrm{j}=1,2,3, \ldots, N_{\mathrm{i}}$ products per firm and $\mathrm{i}=$ $1,2,3, \ldots, I$ firms. Each quality index must be CES in order to ensure that the price aggregator remains CES. Further, by multiplying each price by $\Psi_{\mathrm{ij}}$ we retain the central insight provided by Deaton and Muellbauer's (1980) approach, namely if the ratio of price to quality is lower for good $\mathrm{A}$ than $\mathrm{B}$, ceteris paribus, then good A will be chosen. This is a discrete choice, or a corner solution. Applying Roy's Identity to (1) and simplifying provides the share equations for each choice of firm and product: 


$$
S_{\mathrm{ij}}=\left(\frac{\hat{p}_{\mathrm{ij}}^{1-\sigma_{\mathrm{i}}}}{\sum_{\mathrm{j}=1}^{N_{\mathrm{i}}} \hat{p}_{\mathrm{ij}}^{1-\sigma_{\mathrm{i}}}}\right)\left(\frac{P_{\mathrm{i}}^{1-\sigma}}{\sum_{\mathrm{i}=1}^{N} P_{\mathrm{i}}^{1-\sigma}}\right)
$$

where $P_{\mathrm{i}}=\left(\sum_{\mathrm{j}=1}^{N_{\mathrm{i}}} \hat{p}_{\mathrm{ij}}^{1-\sigma_{\mathrm{i}}}\right)^{1 /\left(1-\sigma_{\mathrm{i}}\right)}$ is the priceaggregator function, or price index, for firm i and $S_{\mathrm{ij}}$ represents the market share (measured as the share of total market expenditure) of product $\mathrm{j}$ sold by firm $\mathrm{i}$. In our application of the NCES to firm and product choice, we also include an outside option to allow for the fact that shoppers can buy fresh fruit from places other than the major retail firms described by our data. Consequently, share expansion can indeed represent category growth for any of the firms considered here. An estimable form of (3) is created by expressing each share in logs and adding an independent and identically distributed (iid) error term, $\mu_{\mathrm{ij}}$ :

$$
\begin{aligned}
& \log \left(S_{\mathrm{ij}}\right)-\left(1-\sigma_{\mathrm{i}}\right) \log \left(\hat{p}_{\mathrm{ij}}\right) \\
& +\log \left(\sum_{\mathrm{j}=1}^{N_{\mathrm{i}}} \hat{p}_{\mathrm{ij}}^{1-\sigma_{\mathrm{i}}}\right)-(1-\sigma) P_{\mathrm{i}} \\
& +\log \left(\sum_{\mathrm{i}=1}^{I} P_{\mathrm{i}}^{1-\sigma}\right)=\mu_{1 \mathrm{ij}}
\end{aligned}
$$

for $\mathrm{i}=1,2,3, \ldots, I$ and $\mathrm{j}=1,2,3, \ldots, N_{\mathrm{i}}$. In the estimation procedure, the set of equations in (4) are estimated with the log-market share as the dependent variable. Estimating (4) on its own, however, provides no information on how firms interact in prices and variety.

To gain insight as to how variety effects price competition, and vice versa, we also specify a model of the supply side of the retail sector. ${ }^{9}$ Estimating equations for each firm's price and variety decision is also necessary because both are clearly endogenous in the NCES demand model described above. Even if neither prices nor variety are strategic variables for retailers, as in the competitive model, they are nevertheless likely to be endogenous for the more subtle reasons cited by Villas-Boas and Winer (1999) and Villas-Boas and Zhao (2003). Namely, both prices and the number of product types offered for sale are set by retail managers who are able to observe market signals that are not observable to the researcher.

\footnotetext{
${ }^{9}$ Our focus here is on interaction only among retailers. Studies by Choi (1991), and more recently Sudhir (2001) and Villas-Boas and Zhao (2003), formally model the nature of manufacturer-retailer interactions but assume a highly simplified retail market. VillasBoas (2003) provides a more detailed analysis of vertical relationships among retailers and manufacturers of a particular consumerpackaged good.
}

For example, display alignment, shelf space, instore specials, mass advertising, and supplier concerns may be taken into account in marketing decisions, and these considerations are unlikely to be independent of price and variety outcomes. In order to address these endogeneity issues, the demand system in (4) is estimated using an instrumental variables approach, which we describe in greater detail below.

Because the first-order conditions for the NCES system are highly nonlinear, we follow Dhar, et al. (2003) in deriving general first-order conditions in terms of elasticities only. ${ }^{10}$ Draganska and Jain (2005) also derive the supply side for firms that choose both price and product-line length, but assume BertrandNash behavior with respect to both variables. The model used here differs from Draganska and Jain in that we allow for a more general Nash behavior and estimate behavior at the firm level, rather than at the individual product level. Focusing on firm-level strategies has both logical and practical appeal. First, managers in a given city do not compare prices with rivals' on an individual product level, but rather category by category. Second, variety is more meaningful on a firm level (number of produce stock keeping units [SKUs]) than with respect to individual product lines (number of different sizes of apple), and this is particularly true for the fresh produce data used in this article. Third, for practical reasons, estimating the entire four-firm and five-product model would create an unreasonably high number of parameters to estimate, particularly given that we include both price and variety reactions. Assuming nonjointness of production, the profit equation for firm $\mathrm{i}$ is written as:

$$
\begin{aligned}
\pi_{\mathrm{i}} & =M \sum_{\mathrm{j} \in N_{\mathrm{i}}} S_{\mathrm{ij}}\left(p_{\mathrm{ij}}-c_{\mathrm{ij}}\right)-g_{\mathrm{i}}\left(N_{\mathrm{i}}\right) \\
& =M S_{\mathrm{i}}\left(P_{\mathrm{i}}-C_{\mathrm{i}}\right)-g_{\mathrm{i}}\left(N_{\mathrm{i}}\right)
\end{aligned}
$$

where $M$ is the total market size, $c_{\mathrm{ij}}$ is the marginal cost of retailing, and $P_{\mathrm{i}}$ and $C_{\mathrm{i}}$ are retail and wholesale CES price indices, respectively. This cost is assumed to be separable between wholesaling and a Generalized Leontief retail unit-cost function, so that unit-retailing costs are written as:

\footnotetext{
${ }^{10}$ Dhar et al. extend the general notation for the first-order conditions of a profit maximizing multiproduct firm presented by Nevo (2001) by demonstrating that the estimation of conduct parameters requires only elasticities from the demand system, along with measures of cost and other supply shifters as required.
} 


$$
c_{\mathrm{ij}}=w_{\mathrm{ij}}+\sum_{\mathrm{k}} \tau_{\mathrm{k}} \nu_{\mathrm{k}}+\sum_{\mathrm{k}} \sum_{\mathrm{l}} \tau_{\mathrm{kl}}\left(\nu_{\mathrm{k}} \nu_{\mathrm{l}}\right)^{1 / 2}
$$

where $w_{\mathrm{ij}}$ is the wholesale (free on board [FOB] ) price of product $\mathrm{j}, \nu_{\mathrm{k}}$ is a vector of input prices that includes retail labor costs, marketing costs, and FIRE (finance, insurance, and real estate) costs, and $\tau_{\mathrm{k}}$ and $\tau_{\mathrm{kl}}$ are parameters to be estimated. Firm profit also includes certain fixed costs of variety, which encompass the costs of either developing and marketing private labels, or introducing and shelving external brands. Draganska and Jain (2005) argue that these costs are convex as greater variety imposes higher costs on the firm. To capture this effect, we model variety costs as a quadratic function: $g_{\mathrm{i}}\left(N_{\mathrm{i}}\right)=\delta_{\mathrm{i} 1} N_{\mathrm{i}}+0.5 \delta_{\mathrm{i} 2} N_{\mathrm{i}}^{2}$, which, of course, implies linear marginal costs of variety.

Unlike Draganska and Jain, we allow for general price and variety behavior by introducing conduct parameters, or conjectural elasticities, with respect to both price and variety. Further, firms are assumed to form expectations of others' reactions to changes in both price and product line. In other words, we estimate cross-variable conduct parameters similar to Kadiyali, Vilcassim, and Chintagunta (1996) so that we can test for whether firms respond to changes in price with changes in product line and vice versa. In this way, the NCES model reflects an inherently "nested" problem in that each firm's prices and product lines are determined by decisions made within other firms as well as for internal considerations. Taking this into account, the first-order condition with respect to the price index of retailer i becomes:

$$
\begin{gathered}
\frac{\partial \pi_{\mathrm{i}}}{\partial P_{\mathrm{i}}}=S_{\mathrm{i}} M+\sum_{\mathrm{k}}\left(P_{\mathrm{i}}-C_{\mathrm{i}}\right) \frac{\partial S_{\mathrm{i}}}{\partial P_{\mathrm{k}}} \frac{\partial P_{\mathrm{k}}}{\partial P_{\mathrm{i}}} M \\
+\sum_{\mathrm{k}}\left(P_{\mathrm{i}}-C_{\mathrm{i}}\right) \frac{\partial S_{\mathrm{i}}}{\partial N_{\mathrm{k}}} \frac{\partial N_{\mathrm{k}}}{\partial P_{\mathrm{i}}} M=0, \\
\mathrm{k}=1,2, \ldots, I
\end{gathered}
$$

Similarly, the first-order condition with respect to variety, or product-line length for retailer i is given by:

$$
\begin{aligned}
\frac{\partial \pi_{\mathrm{i}}}{\partial N_{\mathrm{i}}}= & \sum_{\mathrm{k}}\left(P_{\mathrm{i}}-C_{\mathrm{i}}\right) \frac{\partial S_{\mathrm{i}}}{\partial N_{\mathrm{k}}} \frac{\partial N_{\mathrm{k}}}{\partial N_{\mathrm{i}}} M \\
& +\sum_{\mathrm{k}}\left(P_{\mathrm{i}}-C_{\mathrm{i}}\right) \frac{\partial S_{\mathrm{i}}}{\partial P_{\mathrm{k}}} \frac{\partial P_{\mathrm{k}}}{\partial N_{\mathrm{i}}} M-\delta_{1 \mathrm{i}} \\
& -\delta_{2 \mathrm{i}} N_{\mathrm{i}}=0, \quad \mathrm{k}=1,2, \ldots, I
\end{aligned}
$$

where the terms $\partial P_{\mathrm{k}} / \partial P_{\mathrm{i}}, \partial N_{\mathrm{k}} / \partial P_{\mathrm{i}}, \partial N_{\mathrm{k}} / \partial N_{\mathrm{i}}$, $\partial P_{\mathrm{k}} / \partial N_{\mathrm{i}}$, represent firm i's expectation of firm k's response to changes in its chain-wide "average" price and the variety of products on offer. These equations can be simplified by writing each in terms of demand and response elasticities (Dhar and Cotterill 2003), and measures of total category cost $\left(e_{\mathrm{i}}\right)$ and revenue $\left(r_{\mathrm{i}}\right)$. Doing so results in an estimable system of price :

$$
\begin{aligned}
r_{\mathrm{i}}+ & \sum_{\mathrm{k}}\left(r_{\mathrm{i}}-e_{\mathrm{i}}\right) \varepsilon_{\mathrm{ik}} \varphi_{\mathrm{ik}}+\sum_{\mathrm{k}}\left(r_{\mathrm{i}}-e_{\mathrm{i}}\right) \eta_{\mathrm{ik}} \lambda_{\mathrm{ik}} \\
& =\mu_{2 i}, \quad \mathrm{k}=1,2, \ldots, I
\end{aligned}
$$

and variety equations:

$$
\begin{array}{r}
\delta_{1 \mathrm{i}} N_{\mathrm{i}}-\delta_{2 \mathrm{i}} N_{\mathrm{i}}^{2}-\left(r_{\mathrm{i}}-e_{\mathrm{i}}\right)\left(\eta_{\mathrm{ii}}+\sum_{\mathrm{k}} \eta_{\mathrm{ik}} \alpha_{\mathrm{ik}}\right. \\
\left.+\sum_{\mathrm{k}} \varepsilon_{\mathrm{ik}} \gamma_{\mathrm{ik}}\right)=\mu_{3 \mathrm{i}}, \quad \mathrm{k}=1,2, \ldots, I
\end{array}
$$

where $\varepsilon_{\mathrm{ik}}$ is the price elasticity of demand of product $i$ with respect to the price of firm $\mathrm{k}, \eta_{\mathrm{ik}}$ is the "variety elasticity" of demand of product $i$ with respect to the number of products offered by k, $\varphi_{\mathrm{ik}}$ is the conjectural elasticity of firm k's price with respect to a change in firm i's price, $\lambda_{\mathrm{ik}}$ is the conjectural elasticity of firm k's product-line length with respect to firm i's price, $\alpha_{\mathrm{ik}}$ is the elasticity of firm k's variety response to an increase in offerings by firm $i, \gamma_{i k}$ is the conjectural elasticity of firm k's price response to a change in firm i's variety, and $\mu_{2 i}$ and $\mu_{3 \mathrm{i}}$ are econometric error terms. The expression for retailing costs in (6) is substituted into (9) and (10) prior to estimation.

As a result, the entire system consists of two blocks of equations: (1) the demand block described in (4) that consists of 20 equations (four stores with five products each), (2) the price and variety response block described in (9) and (10) that consists of eight equations in totalfour price response equations and four variety response equations. While estimation of the entire system together would be preferable on efficiency grounds, the size of the problem requires a sequential estimation approach in which the cross-equation restrictions implied by the previous stage are imposed at each iteration. As explained in greater detail below, all parameter estimates are obtained by nonlinear three-stage least squares (NL3SLS) within each block of equations. Because NL3SLS is a nonlinear estimation method, each equation is estimated with the dependent variable in implicit form as shown in (9)-(10) above. 


\section{Data and Estimation Methods}

The retail price, quantity, and promotional data base consists of two years (January 1998December 1999) of weekly scanner data for five products in a single category (fresh fruit) from four major supermarket firms in the LA market. ${ }^{11}$ Retailer-specific data are used to identify competitive interactions among the four retail firms, while product-specific data provide the measure of heterogeneity among products within each firm. Because we are interested in firm-level pricing and variety strategies, the data are aggregated over all stores for each of the four chains. Scanner data for perishable products comprises a number of unique items per product definition, depending upon whether it is bagged or bulk, small or large, or of a particular variety, so we aggregate over individual price-look-up (PLU) codes to the product level for red delicious apples, granny smith apples, fuji apples, bananas, and grapes. Variety is then measured by a simple PLU count for each aggregate product.

The input price data are from various secondary sources. Weekly wholesale prices for the sample of fruits represented here are from the Agricultural Marketing Service (AMS) of the USDA (grapes), the Washington Growers' Clearing House (apples), or the Ecuador Ministry of Agriculture (bananas) and represent shipping-point FOB prices. Retailing costs are measured by an index of wages in retail and wholesale trade, an index of marketing costs, and a composite index of FIRE costs, all from the Bureau of Labor Statistics (BLS). All input-price indices, however, are only available on a monthly basis. Therefore, the price in each week is first set equal to the associated monthly price, and then converted to weekly series using a linear filter similar to Slade (1995) and Besanko, Gupta, and Jain (1998):

$$
\nu_{\mathrm{kt}}=0.25 \hat{v}_{\mathrm{k}, \mathrm{t}-1}+0.50 \hat{v}_{\mathrm{k}, \mathrm{t}}+0.25 \hat{v}_{\mathrm{k}, \mathrm{t}+1}
$$

for input price index $\mathrm{k}$.

In order to capture retail competition at the firm level, all prices represent per-product, per-firm averages and all quantities are expressed on a per-firm basis. Therefore, each grocery chain is essentially regarded as one firm with multiple locations. Further, the "outside option" is calculated in a manner similar to Nevo (2001). Specifically, LA residents are

\footnotetext{
${ }^{11}$ All of the retail scanner data are from Fresh Look Marketing Group, Chicago, IL.
}

assumed to consume each fresh fruit at the national average rate. U.S. per capital fruit consumption values (Economic Research Service (ERS) USDA) are then multiplied by the population of LA county (the market area of the sample firms) to obtain a total market consumption value for each fruit. Prices for each component of the outside option are calculated as expenditure-weighted averages of each type of fruit in the sample. The outside option is then the difference between total LA expenditure and that represented by the sample firms. Any error can be due to differences between LA and national consumption rates, or to fruit purchased outside of the retail channel represented here. If these errors are random, then the parameter estimates remain valid. ${ }^{12}$

Table 1 provides a descriptive summary of the data used to estimate the demand, pricing, and variety equations at the individual firm level, while table 2 shows descriptive statistics for market-level variables. The data show considerable heterogeneity, both among retail firms and among products within each firm. For example, Firm 2 offers the lowest average price, or next to lowest, for all five products, but also shows the greatest variability in price among all sample firms. This suggests that it uses a HI-LO strategy more aggressively than the others. Firm 1, on the other hand, has the smallest market share for all five products and also offers the least variety among all firms. Firm 3 maintains the broadest offering of fresh fruit, but also has the highest prices for most products, with the exception of bananas, for which it has the lowest price. It is often suggested that retailers use bananas as a loss leader due to their broad appeal to a large number of consumers, and firm 3 may be using loss leadership to generate sales for other, high-margin products within its product line. Whether this is in fact the case, however, requires more detailed empirical analysis. Firm 4 has the largest market share for the five sample products $(24.3 \%)$, while firm 1 has the smallest market share $(10.9 \%)$. The firms are relatively similar in terms of the variability of market share as they are clustered between a coefficient of variation of $35.6 \%$ (firm 3 ) and $45.4 \%$ (firm 2). At the market level, table 2 shows that all wholesale prices were very volatile over the sample period-each has a coefficient of variation of over $50 \%$. Further, the outside option,

\footnotetext{
${ }^{12}$ See Nevo (2000, 2001) and Berry, Levinsohn, and Pakes (1995) for an extensive discussion of the role and construction of the outside option in discrete choice models.
} 


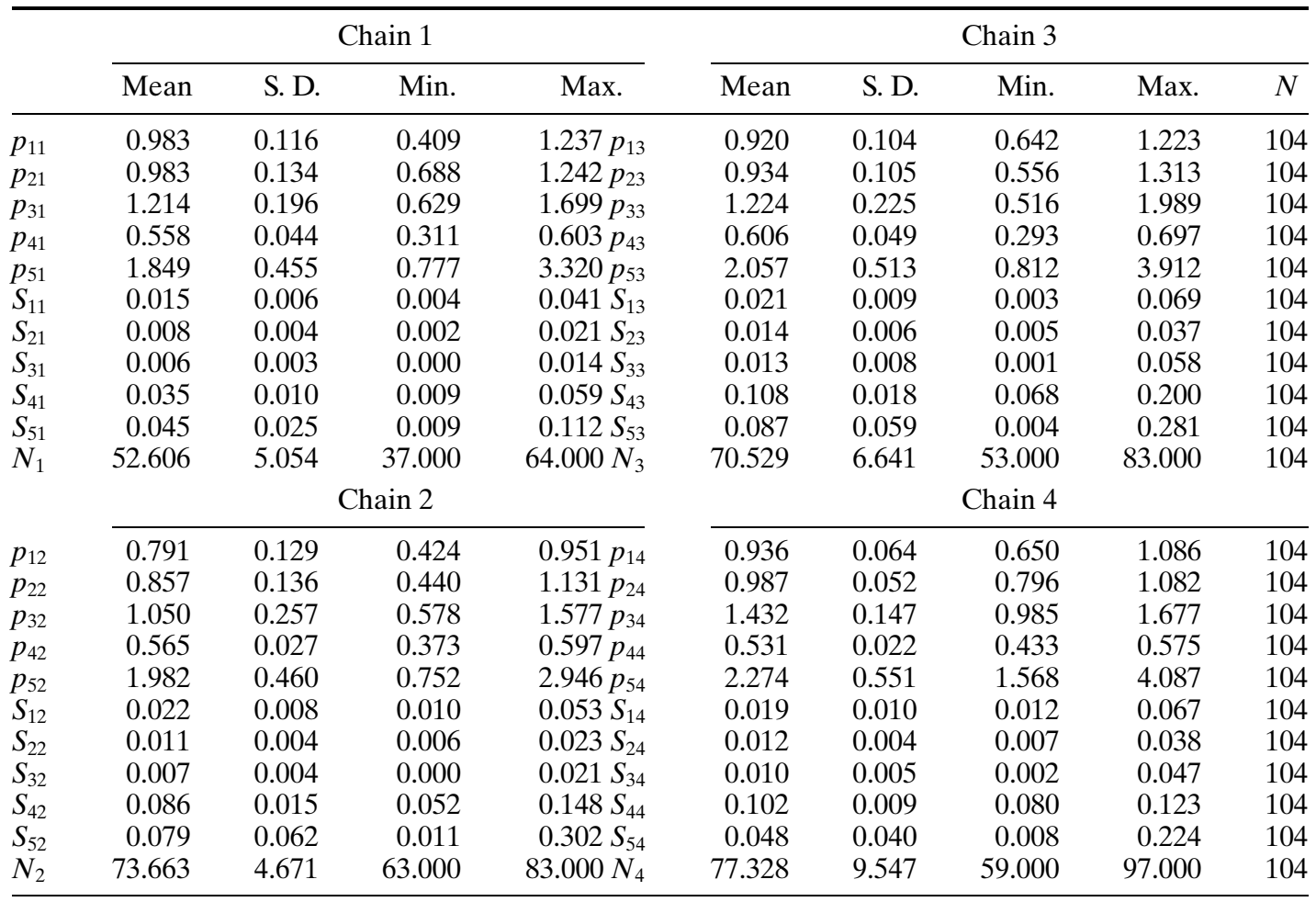

${ }^{\mathrm{a}}$ In this table, $p_{\mathrm{ji}}$ is the price of product $\mathrm{j}$ in firm $\mathrm{i}$, and $S_{\mathrm{ji}}$ is the marginal market share (i.e., share of the entire market) of product $\mathrm{j}$ in firm $\mathrm{i}$. The products are indexed as follows: $\mathrm{j}=1$ is red delicious apples, $\mathrm{j}=2$ is granny smith apples, $\mathrm{j}=3$ is fuji apples, $\mathrm{j}=4$ is bananas, and $\mathrm{j}=5$ is grapes. Firm names are not disclosed for reasons of confidentiality. The variable $N_{\mathrm{i}}$ measures the number of distinct SKUs within each firm i.

or fruit not purchased from any of the sample retailers, consists of only $25 \%$ of the market, so that our data on the top four retailers includes the majority of purchases made in the LA retail produce market.

Although estimating (4), (9), and (10) together is preferred on efficiency grounds, the

\section{Table 2. Summary of LA Retail Scanner Data-Market Level, January 1998- December 1999}

\begin{tabular}{lccccc}
\hline & Mean $^{\mathrm{a}}$ & S.D. & Min & Max & $N$ \\
\hline$v_{1}$ & 3.215 & 0.081 & 3.011 & 3.409 & 104 \\
$v_{2}$ & 6.614 & 0.223 & 6.075 & 7.025 & 104 \\
$v_{3}$ & 3.123 & 0.052 & 2.953 & 3.226 & 104 \\
$w_{1}$ & 0.257 & 0.039 & 0.190 & 0.330 & 104 \\
$w_{2}$ & 0.337 & 0.029 & 0.282 & 0.439 & 104 \\
$w_{3}$ & 0.352 & 0.079 & 0.211 & 0.584 & 104 \\
$w_{4}$ & 0.209 & 0.060 & 0.113 & 0.338 & 104 \\
$w_{5}$ & 0.156 & 0.062 & 0.088 & 0.380 & 104 \\
$S_{0}$ & 0.250 & 0.139 & 0.073 & 0.504 & 104 \\
\hline
\end{tabular}

${ }^{\mathrm{a}}$ In this table, $v_{i}$ is input price $i$ for $i=1,2,3 ; w_{\mathrm{j}}$ is $\mathrm{FOB}$ (wholesale) price $j$ for $j=1,2, \ldots, 5$, and $S_{0}$ is the market share of the outside option. Input prices are indexed as follows: $i=1$ is an index of wages in retail and wholesale trade, $i=2$ is an index of marketing costs, and $i=3$ is an index of FIRE costs. size of the estimation problem required sequential estimation of the demand and supply, or price and variety response blocks. ${ }^{13}$ Elasticity estimates from the system of equations described by (4), therefore, are included in (9) and (10) in order to recover the conjectural elasticity estimates. In both systems, however, prices and variety are clearly endogenous, so an instrumental variable procedure is used for each block of equations. Instruments are selected that are likely to be correlated with the dependent variables, yet uncorrelated with the errors in each equation. For the demand system, the set of instruments includes the set of wholesale fresh fruit prices, the supermarket cost indices described above and lagged values of each product's retail price, number of products offered, and market share. Because of the large number of parameters in the demand system, this set of instruments is still not sufficient to obtain unique estimates of each.

\footnotetext{
13 The second-stage parameter estimates will be consistent, however, because the values estimated in the first stage are appropriate instruments for the endogenous quantities in the second-stage model
} 
Consequently, we follow Villas-Boas (2003), and Draganska and Jain (2005) and interact these instruments with a set of product- and firm-binary-indicator variables.

The first-stage results of the NL3SLS procedure provides us with some reassurance that the set of instruments is a good one. Regressing price on the set of instruments yields an $R^{2}$ of 0.986 , while regressing variety on the same instruments gives an $R^{2}$ of 0.983 . In the price regression, $45.7 \%$ of the instruments are statistically significant at a $10 \%$ level, while $44.3 \%$ are significant in the variety regression. The same set of instruments are also used to estimate the supply block. Both blocks of equations are estimated using NL3SLS.

Price and variety responses by rival firms are identified in the system by the nonlinearity of demand in both price and variety (VillasBoas). Although the NCES, of course, has constant elasticities of substitution, price and variety elasticities vary over time, firms and products so there is sufficient variation to identify all the response parameters in the system.

\section{Results and Discussion}

We assess the goodness-of-fit of both blocks of equations with a system $R^{2}$ as well as a Wald chi-square test statistic that compares the estimated and a null model that consists of constant terms only. The results in table 3 indicate that the model provides a good fit to the data, providing an $R^{2}$ value of 0.8051 and easily rejecting the null hypothesis that all population parameters are zero. Tests of the price and variety response hypotheses outlined above are conducted using the conjectural elasticity values estimated in the supply-side model.

Table 3. Nested CES Parameter Estimates: LA Retail Fresh Fruit, 1998-99

\begin{tabular}{|c|c|c|c|c|c|c|c|c|}
\hline \multirow[b]{2}{*}{ Parameters } & \multicolumn{2}{|c|}{ Firm 1} & \multicolumn{2}{|c|}{ Firm 2} & \multicolumn{2}{|c|}{ Firm 3} & \multicolumn{2}{|c|}{ Firm 4} \\
\hline & Estimate & SE & Estimate & SE & Estimate & SE & Estimate & SE \\
\hline$\sigma_{i}$ & $0.040^{*}$ & 0.003 & $0.176^{*}$ & 0.006 & $0.123^{*}$ & 0.004 & $0.202^{*}$ & 0.007 \\
\hline$\beta_{1 i 1}$ & $6.199^{*}$ & 1.023 & $3.620^{*}$ & 1.134 & -0.948 & 1.003 & $3.668^{*}$ & 1.021 \\
\hline$\beta_{2 i 1}$ & 1.074 & 0.984 & $8.705^{*}$ & 0.977 & $9.082^{*}$ & 0.905 & $16.652^{*}$ & 0.961 \\
\hline$\beta_{3 i 1}$ & $5.963^{*}$ & 1.007 & $-11.433^{*}$ & 1.093 & $-6.524^{*}$ & 1.020 & $-17.874^{*}$ & 1.134 \\
\hline$\beta_{4 i 1}$ & 0.096 & 0.262 & $0.298^{*}$ & 0.087 & $0.255^{*}$ & 0.118 & $0.532^{*}$ & 0.091 \\
\hline$\beta_{1 i 2}$ & $-18.536^{*}$ & 1.289 & -0.533 & 1.051 & -2.050 & 1.224 & 0.269 & 1.287 \\
\hline$\beta_{2 i 2}$ & -0.569 & 0.961 & $9.526^{*}$ & 0.862 & $16.586^{*}$ & 1.198 & $4.580^{*}$ & 0.930 \\
\hline$\beta_{3 i 2}$ & $2.351^{*}$ & 0.984 & $-10.341^{*}$ & 1.026 & $-16.326^{*}$ & 1.264 & $-4.375^{*}$ & 1.026 \\
\hline$\beta_{4 i 2}$ & 0.209 & 0.248 & $0.298^{*}$ & 0.085 & 0.229 & 0.118 & $0.532^{*}$ & 0.095 \\
\hline$\beta_{1 i 3}$ & $23.458^{*}$ & 1.449 & $6.678^{*}$ & 1.181 & $15.514^{*}$ & 1.293 & $10.814^{*}$ & 1.339 \\
\hline$\beta_{2 i 3}$ & -0.807 & 0.975 & 2.114* & 1.065 & 0.926 & 0.889 & $5.891^{*}$ & 0.869 \\
\hline$\beta_{3 i 3}$ & $4.151^{*}$ & 1.010 & 1.730 & 1.009 & $1.959^{*}$ & 0.979 & $-9.490^{*}$ & 1.053 \\
\hline$\beta_{4 i 3}$ & 0.499 & 0.255 & $0.378^{*}$ & 0.088 & $0.285^{*}$ & 0.114 & $0.519^{*}$ & 0.097 \\
\hline$\beta_{1 i 4}$ & $-2.297^{*}$ & 1.132 & 7.908* & 1.069 & $-7.616^{*}$ & 1.159 & $-4.535^{*}$ & 1.238 \\
\hline$\beta_{2 i 4}$ & $10.730^{*}$ & 1.034 & $22.073^{*}$ & 1.427 & $17.275^{*}$ & 1.097 & $10.838^{*}$ & 0.979 \\
\hline$\beta_{3 i 4}$ & $-4.073^{*}$ & 1.006 & $-23.600^{*}$ & 1.433 & $-9.853^{*}$ & 0.980 & $-9.316^{*}$ & 0.968 \\
\hline$\beta_{4 i 4}$ & -0.353 & 0.282 & 0.109 & 0.097 & $0.272^{*}$ & 0.116 & $0.557^{*}$ & 0.088 \\
\hline$\beta_{1 i 5}$ & 1.541 & 1.002 & $-4.797^{*}$ & 1.130 & $-2.413^{*}$ & 1.035 & $11.474^{*}$ & 1.370 \\
\hline$\beta_{2 i 5}$ & $15.491^{*}$ & 1.206 & $2.623^{*}$ & 1.020 & $3.772^{*}$ & 1.088 & $5.451^{*}$ & 0.931 \\
\hline$\beta_{3 i 5}$ & $-5.175^{*}$ & 0.879 & -0.985 & 0.646 & $-1.535^{*}$ & 0.581 & $-2.470^{*}$ & 0.516 \\
\hline$\beta_{4 i 5}$ & $0.962^{*}$ & 0.236 & $0.512^{*}$ & 0.098 & $0.368^{*}$ & 0.128 & $0.571^{*}$ & 0.101 \\
\hline$\sigma$ & $0.870^{*}$ & 0.007 & & & & & & \\
\hline$q$ & $1,322.349$ & & & & & & & \\
\hline$R^{2}$ & 0.805 & & & & & & & \\
\hline$x^{2}$ & $11,214.79^{*}$ & & & & & & & \\
\hline
\end{tabular}

${ }^{a}$ In this table, parameter $\beta_{\mathrm{kij}}$ refers to the demand-parameter estimate for variable $k$, firm i, product $\mathrm{j}$, where $k=1$ is the product-chain-specific preference parameter, $k=2$ is the direct promotion effect, $k=3$ is the price* promotion interaction effect, and $k=4$ is the variety effect, measured by $N_{\mathrm{i}}$, the average number of products offered per firm per period, $j=1$ is red delicious apples, $j=2$ is granny smith apples, $j=3$ is fuji apples, $j=4$ is bananas, and $j=5$ is grapes. A single asterisk indicates significance at a $5 \%$ level, where "SE" is the standard error of the parameter estimate. The $\sigma_{i}$ are elasticities of substitution among products within firm i, while $\sigma$ is the elasticity of substitution among firms. Seasonal indicator variables are suppressed to conserve space, but are all significantly different from zero. The NL3SLS objective function value is given by $q$ (Greene 1993) while $R^{2}$ is the system-coefficient of determination (McElroy 1977). The $\chi^{2}$ test statistic compares the estimated model to the "null model" with constant terms only. At $5 \%$ and 125 degrees of freedom, the critical chi-square value is 152.094 
However, there is also considerable interest in the validity of the CES demand system and the insights it provides. If the elasticity of substitution among firms is equal to 1.0, then there is no need to consider a nested system: Consumers in this case would regard retail firms as perfect substitutes. Similarly, at the product level, an elasticity of substitution of 1.0 implies that all products are perfect substitutes. Based on the results in table 3 , a Wald chi-square statistic for the hypothesis that $\sigma=1.0$ is 17.50 , while the critical value at one degree of freedom at a $5 \%$ level is 3.84 . Therefore, we clearly reject the null hypothesis, which suggests that a two-level nested system is preferred. Among the product-level elasticities of substitution, we again reject the null hypothesis that $\sigma_{\mathrm{i}}=1.0$ in each case, which implies that different types of fruit are indeed imperfect substitutes for one another. ${ }^{14}$ Further, DurbinWatson tests for first-order autocorrelation among the errors of each equation in the demand system failed to reject the null hypothesis of no autocorrelation for all products in all stores $\left(H_{0}: \rho_{i j}=0\right)$.

Anderson and de Palma (1992) raise the issue of whether we should expect greater differentiation (less substitutability) within a particular firm or among different firms. In the supermarket example, consumers choose many types of goods to fill fundamentally differing needs, but each firm sells roughly similar types of products. Consequently, we expect to find greater product differentiation within each firm than retailer differentiation across firms. The results in table 3 support this, as the product-level substitution elasticities are significantly lower than the firm-level estimate. Interpreted as measures of heterogeneity, these estimates also mean that differences among products are perceived to be far greater than differences among firms. Although fourpoint estimates of the product-level substitution elasticities do not permit a formal test of the hypothesis that greater product heterogeneity leads to more variety, or longer product lines, the estimates in table 3 provide some evidence contrary to this idea. Whereas firm 1 offers only 52.6 products on average and has a substitution elasticity of 0.040 , firm 4 offers 77.33 products and has a substitution elasticity among products of 0.202 - the highest of all our

\footnotetext{
${ }^{14}$ The test statistic for the null hypothesis that $\sigma_{1}=1.0$ is 303.689 , for $\sigma_{2}=1.0$ is 147.053 , for $\sigma_{3}=1.0$ is 219.775 , and for $\sigma_{4}=1.0$ is 119.046 . In each case, the test statistic is chi-square distributed with one degree of freedom.
}

sample firms. Anderson's argument maintains that if products are not readily substitutable for one another, a firm can introduce more brands without fear of cannibalizing existing sales. However, as Hamilton (2003) points out, the cost of cannibalized sales is also larger in this case, as retail margins increase with product differentiation. The empirical model provides some evidence that the latter effect is indeed the dominant one.

The remaining parameters in the demand system comprise the product-level quality functions, $\Psi_{\mathrm{ij}}$. Whereas Morey et al. (2001) assume common quality parameters among each of their primary-level choices, this alternative was rejected in the LA retail data in favor of product- and firm-specific parameters. In each case, a positive parameter estimate suggests that the perceived "quality" or underlying demand for the product rises in the associated variable or, in the case of the intercept term, that the inherent preference for the good in question is higher than average. In this respect, the results in table 3 indicate that consumers in three of the four firms express a preference for red delicious apples, while consumers in all firms tend to favor fuji apples. Perhaps surprising, given the importance of bananas to fresh produce retailing, consumers in three of four firms tend to show a negative preference for bananas. Given the importance consumers place in the quality of a firm's fresh produce, retailers are particularly interested in the effectiveness of price-promotion programs for fresh products. For virtually all products and firms, the promotion variable represents a strongly significant influence on demand. A positive value for the binary sales indicator means that demand increases during a sale, while a negative interaction term means that demand also becomes less elastic. Both of these outcomes are desirable from the retailer's point of view. While it is not the primary objective of this article, it would be possible to calculate the profit implications of a sale in each case with the CES demand estimates.

With respect to the demand for variety, the $\beta_{\mathrm{ik} 4}$ parameter shows the effect on the demand for product $\mathrm{k}$ in firm $\mathrm{i}$ of increasing the number of products offered within the fruit category. Consumers may value a variety of choices in fresh fruit if they are easily satiated in either the taste or nutritional attributes they desire when consuming fruit (McAlister and Pesemier 1982; Chintagunta 1998), if they seek a hedge against future changes in taste (Walsh 1995) or if they desire more attributes than one 


\begin{tabular}{|c|c|c|c|c|c|c|c|c|}
\hline \multirow[b]{3}{*}{ With Respect to: ${ }^{\mathrm{a}}$} & \multicolumn{8}{|c|}{ Elasticity of: } \\
\hline & \multicolumn{2}{|c|}{$Q_{1}$} & \multicolumn{2}{|c|}{$Q_{2}$} & \multicolumn{2}{|c|}{$Q_{3}$} & \multicolumn{2}{|c|}{$Q_{4}$} \\
\hline & $\varepsilon_{1 k}$ & SE & $\varepsilon_{2 k}$ & SE & $\varepsilon_{3 k}$ & SE & $\varepsilon_{4 k}$ & SE \\
\hline$P_{1}$ & $-1.151^{*}$ & 0.011 & $0.146^{*}$ & 0.011 & $0.146^{*}$ & 0.011 & $0.146^{*}$ & 0.011 \\
\hline$P_{2}$ & $0.321^{*}$ & 0.048 & $-0.976^{*}$ & 0.048 & $0.321^{*}$ & 0.048 & $0.321^{*}$ & 0.048 \\
\hline$P_{3}$ & $0.207^{*}$ & 0.020 & $0.207^{*}$ & 0.020 & $-1.090^{*}$ & 0.020 & $0.207^{*}$ & 0.020 \\
\hline \multirow[t]{2}{*}{$P_{4}$} & $0.624^{*}$ & 0.072 & $0.624^{*}$ & 0.072 & $0.624^{*}$ & 0.072 & $-0.674^{*}$ & 0.072 \\
\hline & $\eta_{1 k}$ & $\mathrm{Se}$ & $\eta_{2 k}$ & $\mathrm{Se}$ & $\eta_{3 k}$ & $\mathrm{Se}$ & $\eta_{4 k}$ & $\mathrm{Se}$ \\
\hline$N_{1}$ & $0.179^{*}$ & 0.004 & $-0.022^{*}$ & 0.004 & $-0.022^{*}$ & 0.004 & $-0.022^{*}$ & 0.004 \\
\hline$N_{2}$ & $-0.226^{*}$ & 0.042 & $0.685^{*}$ & 0.042 & $-0.226^{*}$ & 0.042 & $-0.226^{*}$ & 0.042 \\
\hline$N_{3}$ & $-0.071^{*}$ & 0.014 & $-0.071^{*}$ & 0.014 & $0.369^{*}$ & 0.014 & $-0.071^{*}$ & 0.014 \\
\hline$N_{4}$ & $-0.629^{*}$ & 0.110 & $-0.629^{*}$ & 0.110 & $-0.629^{*}$ & 0.110 & $0.675^{*}$ & 0.110 \\
\hline
\end{tabular}

${ }^{\text {a }}$ In this table, all subscripts refer to chain i, so $Q_{i}$ is the volume of sales from firm i, $P_{\mathrm{i}}$ is the price index for firm i, and $N_{\mathrm{i}}$ is the number of products offered for sale by firm i. All elasticities are calculated at sample means. A single asterisk indicates significance at a $5 \%$ level where "SE" is the standard error of the parameter estimate.

item can provide (Farquhar and Rao 1976). Product variants in this case may mean different sizes of apple, alternative package forms, or different colors of grape, for example. Although Draganska and Jain (2005) provide arguments for, and show empirical support for, a concave effect of variety on market share, here we maintain a linear relationship to keep the model as parsimonious as possible. In general, the results tend to be broadly positive, particularly in the case of fresh grapes, where many would argue that variety not only appeals to consumers' nutritional needs for diversity, but is also visually appealing as well. These results are similar to Draganska and Jain (2005) in yogurt or Bayus and Putsis (1999) in personal computers.

Next, consider firm-level strategies. Table 4 presents estimates of "fresh fruit" price elasticities for each firm. Consistent with common notions of the competitiveness of the supermarket sector, the price elasticity of demand for each firm is near unity, except for the fourth. As expected, the firms are substitutes for each other and, in general, strong substitutes both in an economic and a statistical sense. With respect to variety elasticities, all of the own elasticities are positive and significant, while the cross-elasticities are negative and significant. These elasticities provide some potentially valuable information. For example, the fact that the second and fourth firms both face price-inelastic demand, and relatively highvariety elasticities suggests that these firms may benefit from higher prices and longer product lines among their fresh fruit. However, greater insight into the strategic value of these changes is provided by the supply-side estimates of each firm's price and variety response.

These estimates are shown in table 5. Based on the $R^{2}$ value and chi-square test results reported in this table, the model clearly provides a good fit to the data. As in Vilcassim, Kadiyali, and Chintagunta (1999), each structural equation allows for firm-specific "multiple interactions" or expected price and variety responses by rivals to a change in variety, or to a change in price. Given that these responses are derived in a Nash equilibrium framework, all are assumed to be optimal given the choices made by other firms. By assuming general Nash behavior on the part of all firms, we offer a more comprehensive analysis of product-line decisions than Draganska and Jain (2005), who assume Bertrand-Nash (zero conduct parameters) in both prices and variety. With respect to price behavior, the conjectural elasticity estimates presented in the top panel show how rivals are anticipated to react to changes in the price of firm i. If the estimate is greater than zero, rival firms are expected to raise their prices in response to a rise in firm i's price in a cooperative way. Clearly, the results in table 5 indicate that the retailers are far from competitive $\left(\varphi_{i k}=0\right)$. Rather, the estimates in each case suggest a range from mildly cooperative (firm 2 with respect to firm 4) to strongly cooperative (firm 2 with respect to firm 3 ). These results also suggest that price and variety are strategic complements as each firm expects its rivals to increase the number of products they offer in response to an increase in the firm's own price. One explanation for a positive variety 
Table 5. LA Supermarket Price and Variety Response Elasticities, 1998-99

\begin{tabular}{|c|c|c|c|c|c|c|c|c|}
\hline & \multicolumn{2}{|c|}{ Firm 1} & \multicolumn{2}{|c|}{ Firm 2} & \multicolumn{2}{|c|}{ Firm 3} & \multicolumn{2}{|c|}{ Firm 4} \\
\hline & Estimate & $t$-Ratio & Estimate & $t$-Ratio & Estimate & $t$-Ratio & Estimate & $t$-Ratic \\
\hline$\varphi_{i 1}$ & 1.000 & NA & $0.403^{*}$ & 0.023 & $0.455^{*}$ & 0.034 & $0.232^{*}$ & 0.005 \\
\hline$\varphi_{i 2}$ & $0.458^{*}$ & 0.020 & 1.000 & NA & $0.158^{*}$ & 0.020 & $0.136^{*}$ & 0.004 \\
\hline$\varphi_{i 3}$ & $0.565^{*}$ & 0.023 & $0.678^{*}$ & 0.024 & 1.000 & NA & $0.127^{*}$ & 0.004 \\
\hline$\varphi_{i 4}$ & $0.326^{*}$ & 0.015 & $0.072^{*}$ & 0.016 & $0.239^{*}$ & 0.017 & 1.000 & NA \\
\hline$\lambda_{i 1}$ & $1.000^{*}$ & NA & $0.126^{*}$ & 0.003 & $1.210^{*}$ & 0.049 & $0.211^{*}$ & 0.005 \\
\hline$\lambda_{i 2}$ & $0.425^{*}$ & 0.024 & 1.000 & NA & $0.186^{*}$ & 0.032 & $0.221^{*}$ & 0.006 \\
\hline$\lambda_{i 3}$ & $0.149^{*}$ & 0.003 & $0.683^{*}$ & 0.022 & 1.000 & NA & 0.053 & 0.041 \\
\hline$\lambda_{i 4}$ & $0.134^{*}$ & 0.011 & $0.030^{*}$ & 0.013 & $0.139^{*}$ & 0.012 & 1.000 & NA \\
\hline$\tau_{i 1}$ & $0.104^{*}$ & 0.050 & $1.969^{*}$ & 0.098 & $0.608^{*}$ & 0.027 & $0.458^{*}$ & 0.029 \\
\hline$\tau_{i 3}$ & $-0.407^{*}$ & 0.052 & $1.347^{*}$ & 0.051 & $0.824^{*}$ & 0.044 & $-0.102^{*}$ & 0.032 \\
\hline$\tau_{i 13}$ & $0.010^{*}$ & 0.004 & $0.424^{*}$ & 0.043 & $0.142^{*}$ & 0.010 & 0.081* & 0.011 \\
\hline$\delta_{i 1}$ & $-2.826^{*}$ & 0.137 & $-1.540^{*}$ & 0.185 & $0.077^{*}$ & 0.032 & $2.428^{*}$ & 0.030 \\
\hline$\delta_{i 2}$ & $0.371^{*}$ & 0.014 & $0.859^{*}$ & 0.053 & 10.999* & 0.037 & $10.909^{*}$ & 0.039 \\
\hline$\gamma_{i 1}$ & 1.000 & NA & -0.149 & 0.080 & $0.082^{*}$ & 0.009 & $0.052^{*}$ & 0.011 \\
\hline$\gamma_{i 2}$ & $-0.210^{*}$ & 0.055 & 1.000 & NA & $-0.058^{*}$ & 0.008 & $-0.043^{*}$ & 0.006 \\
\hline$\gamma_{i 3}$ & $0.412^{*}$ & 0.005 & 1.118* & 0.075 & 1.000 & NA & $0.017^{*}$ & 0.007 \\
\hline$\gamma_{i 4}$ & $0.160^{*}$ & 0.056 & $-0.566^{*}$ & 0.076 & -0.001 & 0.002 & 1.000 & NA \\
\hline$\alpha_{i 1}$ & 1.000 & NA & $1.155^{*}$ & 0.073 & 0.013 & 0.018 & 0.015 & 0.014 \\
\hline$\alpha_{i 2}$ & $0.146^{*}$ & 0.006 & 1.000 & NA & $-0.035^{*}$ & 0.011 & $-0.018^{*}$ & 0.009 \\
\hline$\alpha_{i 3}$ & $1.058^{*}$ & 0.007 & $1.306^{*}$ & 0.074 & $1.000^{*}$ & NA & 0.009 & 0.009 \\
\hline$\alpha_{i 4}$ & $0.380^{*}$ & 0.046 & $-0.309^{*}$ & 0.055 & $0.002^{*}$ & -0.013 & 1.000 & NA \\
\hline$q$ & 437.705 & & & & & & & \\
\hline$x^{2}$ & 212.734 & & & & & & & \\
\hline$R^{2}$ & 0.996 & & & & & & & \\
\hline
\end{tabular}

${ }^{a}$ In this table, $\varphi_{\mathrm{ik}}$ is the conjectural elasticity of firm k's price with respect to price changes by firm i, $\lambda_{\mathrm{ik}}$ is the conjectural elasticity of firm k's variety with respect to price changes by firm $i, \alpha_{i k}$ is the conjectural elasticity of firm k's variety with respect to the number of products offered by firm i, $\gamma_{i k}$ is the conjectural elasticity of firm k's price with respect to the number of products offered by firm i, and $\tau_{i l}$ and $\delta_{\text {im }}$ are parameters of the retailing and variety cost functions, respectively. To keep the response-system parameter space as small as possible, two input price indices are used: retail and wholesale wages and advertising costs. A single asterisk indicates significance at a 5\% level, where "SE" is the standard error of the parameter estimate. $q$ is the NL3SLS objective function value, while $R^{2}$ is the system-coefficient of determination (McElroy 1977). At $5 \%$ and 60 degrees of freedom, the critical chi-square value is 79.082.

response to price is as follows: If firm i raises its retail price, this allows firm $\mathrm{j}$ to capture market share, and firm $\mathrm{j}$ will tend to increase its own retail price in response. To maintain its higher iso-profit curve, and prevent erosion of market share back to firm $i$, firm $\mathrm{j}$ increases variety as well. Higher prices appear to intensify variety competition among retailers. As a result, supermarkets appear to behave cooperatively in their pricing decisions for fresh fruit, both in response to rival price and product-line choices.

The bottom panel of table 5 shows that variety decisions are less uniform with respect to their implications for retailer strategy. With respect to the expected variety response of rivals to changes in a firm's own product variety (the $\alpha_{i k}$ parameters), a positive elasticity suggests that product lines are strategic complementsif one firm lengthens its product line, the other firms respond by increasing the number of varieties they offer as well. It is unclear whether variety proliferation by one firm leads to such reciprocation by its rivals. Firm 1 expects all retailers to respond to an increase in its product line with countervailing increases in their own product lines, but firms 3 and 4 expect firm 2 to counter an increase in product variety with a contraction in its product line.

The $\gamma_{\text {ik }}$ parameters in table 5 show the conjectural elasticity of firm k's price with respect to the number of products offered by firm i. A positive elasticity, therefore, suggests that product lines are strategic complements-if one firm product line, it will be able to raise its price, thus leaving more of the market for the other firms. As in the case of a simple price increase described above, with more market share the other firm can raise its price to extract more surplus (as suggested by the positive $\alpha_{i k}$ elasticities in table 5), or may either shrink their product lines to reduce cost, or lengthen them to build more pricing power. Nonetheless, it is unclear from table 5 whether variety competition softens or stiffens price 
competition. Firm 1 appears to make product line decisions on the expectation that firm 2 will respond to an increase in variety with a price decrease, but firms 3 and 4 will respond in a cooperative fashion with price increases. Moreover, each firm expects firm 3 to respond cooperatively to a product-line expansion. The lack of uniformity of variety-induced responses may be due to the fact that changes in product line are not generally as transparent as prices. Supermarkets tend not to advertise many of the minor products they offer, but typically publish as many prices as possible on a weekly basis. However, we can make a general conclusion that retailers, on average, appear to cooperate in both price and product-line decisions.

Further, because price elasticities in the CES model depend upon the elasticity of substitution among products, the results in table 5 can also be interpreted as indirect tests of the firm-heterogeneity hypothesis outlined in the "introduction" section. In the lower block of results shown in table 5, a positive conjectural elasticity estimate $\left(\alpha_{\mathrm{ik}}\right)$ suggests that firm i will offer more products for sale the higher the cross-price elasticity of demand, or the less heterogeneous it perceives the retail market to be. This finding is consistent with the theoretical predictions of both Hamilton (2003) and Anderson and de Palma (1992). The intuition for this is that if firms are largely viewed as homogeneous by consumers, then each will seek to differentiate itself by offering a greater range of products, increasing overall demand in the market by drawing consumption from the outside good. If doing so causes other firms to raise their prices in response to the overall increase in demand, then they each have further incentive to offer more variety. Although this process is limited by the rising cost of variety (note the convexity of each of the variety cost functions in table 5), it can perhaps explain in part the rise of supercenters and other "big box" retailers in markets such as children's toys, consumer electronics, and books.

\section{Conclusions and Implications}

This article provides some empirical evidence on the strategic interaction of pricing and product-line decisions made by supermarket retailers. Theoretical models of price and variety competition suggest that retailer heterogeneity reduces variety, or the length of a firm's product line, while product heterogene- ity increases equilibrium variety. While other studies investigate this question using restrictive, nested-logit-based models, this is the first to empirically test the variety/heterogeneity relationship using a flexible, nested CES model.

The data used in this article consists of two years of weekly scanner data for four major retail firms in the LA market. We use data from an unbranded, fresh product category in order to minimize the influence of manufacturer interference in retail-sales decisions and to gain access to accurate and relevant wholesale price data. These data are used to estimate a fully structural system of fresh fruit demand and first-order conditions with respect to firm-level prices and product numbers. With this approach, the estimated conjectural elasticities represent retailers' response to firm heterogeneity in price and variety strategies.

Estimates of the demand system provide a number of interesting results. First, we find a lower elasticity of substitution among products within each firm than among firms, as expected given the similarity of product offerings among supermarkets. Second, we find considerable support for research among consumer product goods retailing (Chintagunta 2002) that finds price promotion to be highly effective in increasing product-level market share. Third, variety does indeed have a strongly positive impact on sales volume in a particular product line. Fourth, we find that sales at the firm level are nearly approximately unit-elastic with respect to price, and uniformly positively related to firm-level measures of variety.

Using the demand system estimates, we then estimate price and variety response equations that allow for multiple strategic interactions between rival firm's price and variety decisions. Of primary interest among these estimates, we find that each firm tends to follow a "cooperative" or complementary variety strategy with respect to certain rivals, but that such cooperation does not exist among all retailers. Following different variety strategies with respect to some rivals is likely driven by perceived proximities in other respects, such as location, price levels, or private-label strategies. Further, we use these estimates to test the hypothesis that greater firm-level heterogeneity leads to a smaller assortment of products offered per firm. We find some support for this hypothesis; however, the results do not support the corollary hypothesis of Anderson and de Palma (1992) that greater product-level 
heterogeneity leads to longer product lines. This result is consistent with the countervailing effects of product variety suggested by Hamilton (2003).

While this research provides many implications for the extent of competitive interactions among supermarket retailers, perhaps the most important concerns the consequences for how the supermarket industry is likely to evolve. Driven by factors outside their immediate market niche, namely competition from other store formats, traditional supermarkets of the type we study here have been reducing retail prices in real terms in a number of categories. The empirical model suggests that such reductions in price are likely to lead product variety to respond in the same direction, leading to smaller product assortments and shorter product lines. In fact, this is precisely what is occurring now. Through "efficient assortment" and category management programs, supermarkets are reducing SKU counts throughout the store in order to save inventory and handling costs as well as to allow the introduction of their own private-label brands.

\section{References}

Ackerberg, D., and Rysman. 2002. "Unobserved Product Differentiation in Discrete Choice Models: Estimating Price Elasticities and Welfare Effects." Paper presented at the 5th Biennial Conference on Industrial Organization in the Food Industry. INRA-IDEI, Toulouse, France. June.

Anderson, S.P., and A. de Palma. 1992. "Multiproduct Firms: A Nested Logit Approach." Journal of Industrial Economics 40:261-75.

Bayus, B.L., and W.P. Putsis, Jr. 1999. "Product Proliferation: An Empirical Analysis of Product Line Determinants and Market Outcomes." Marketing Science 18:137-53.

Berry, S. 1994. "Estimating Discrete Choice Models of Product Differentiation." RAND Journal of Economics 25:242-62.

Berry, S., J. Levinsohn, and A. Pakes. 1995. "Automobile Prices in Market Equilibrium." Econometrica 63:841-90.

Besanko, D., S. Gupta, and D. Jain. 1998. "Logit Demand Estimation under Competitive Pricing Behavior: An Equilibrium Framework." Management Science 44:1533-47.

Blackorby, C., R. Boyce, and R. Russell. 1978. "Estimation of Demand Systems Generated by the
Gorman Polar Form: A Generalization of the S-Branch Utility Tree." Econometrica 46:34563.

Brander, J.A., and J. Eaton. 1984. "Product Line Rivalry." American Economic Review 74:32334.

Brown, M., and D. Heien. 1972. "The S-Branch Utility Tree: A Generalization of the Linear Expenditure System." Econometrica 40:73747.

Brownstone, D., and K. Train. 1999. "Forecasting New Product Penetration with Flexible Substitution Patterns." Journal of Econometrics 89:109-29.

Chiang, J. 1991. "A Simultaneous Approach to the Whether, What, and How Much to Buy Questions." Marketing Science 10:297-15.

Chintagunta, P.K. 1993. "Investigating Purchase Incidence, Brand Choice and Purchase Quantity Decisions of Households." Marketing Science 12:184-208.

. 1998. "Inertia and Variety Seeking in a Model of Brand-Purchase Timing." Marketing Science 17:253-70.

. 2002. "Investigating Category Pricing Behavior at a Retail Chain." Journal of Marketing Research 39:141-54.

Chintagunta, P.K., J.P. Dube, and V. Singh. 2002. "Market Structure across Stores: An Application of a Random Coefficients Logit Model with Store Level Data." Econometric Models in Marketing 16:191-221.

Choi, S.C. 1991. "Price Competition in a Channel Structure with a Common Retailer." Marketing Science 10:271-96.

Deaton, A., and J. Muellbauer. 1980. Economics and Consumer Behavior. Cambridge, U.K.: Cambridge University Press.

de Palma, A., R. Lindsey, B. Von Hohenbalken, and D.S. West. 1994. "Spatial Price and Variety Competition in an Urban Retail Market: A Nested Logit Analysis." International Journal of Industrial Organization 12:331-57.

Dhar, T.P., J.-P. Chavas, R.W. Cotterill, and B.W. Gould. 2003. "An Econometric Analysis of Brand Level Strategic Pricing between Coca Cola and Pepsi Inc.” Working paper, Food Systems Research Group, University of Wisconsin Madison, June.

Dhar, T., and R.W. Cotterill. 2003. "Oligopoly Pricing with Differentiated Products: The Boston Fluid Milk Market Channel." Paper presented at AAEA annual meeting, Montreal, Canada. August.

Dixit, A.K., and J.E. Stiglitz. 1977. "Monopolistic Competition and Optimum Product Diversity." American Economic Review 67:297-308. 
Dobson, G., and S. Kalish 1988. "Positioning and Pricing a Product Line." Marketing Science 7:107-25.

Draganska, M., and D. Jain. 2005. "Product-Line Length as a Competitive Tool." Journal of Economics and Management Strategy 14:1-28.

Dube, J.P. 2004. "Multiple Discreteness and the Demand for Carbonated Soft Drinks." Management Science 23:66-81.

Ecuador Ministry of Agriculture. 2004. "Agriculture Information System." Available at www.sica.gov.ec/ingles/cadenas/banano. June.

Farquhar, P., and V. Rao 1976. "A Balance Model for Evaluating Subsets of Multiattribute Items.” Management Science 5:528-39.

Food Marketing Institute. 2004. Trends in the United States: Consumer Attitudes and the Supermarket, 2004. Washington DC: The Research Department.

Greene, W.H. 1993. Econometric Analysis, 2nd. ed., Englewood Cliffs, NJ:Prentice-Hall.

Hamilton, S. 2003. "Variety Competition." Working paper, Department of Economics and Business, University of Central Florida, Orlando, FL, August.

Hanemann, W.M. 1984. "Discrete/Continuous Models of Consumer Demand." Econometrica 52:541-61.

Hendel, I. 1999. "Estimating Multiple-Discrete Models: An Application to Computerization Returns." Review of Economic Studies 66:42346.

Kadiyali, V., P. Chintagunta, and N. Vilcassim. 1996. "Empirical Analysis of Competitive Product Line Pricing Decisions: Lead, Follow, or Move Together." Journal of Business 69:45987.

Kadiyali, V., P. Chintagunta, and N. Vilcassim. 1999. "Product Line Extensions and Competitive Market Interactions: An Empirical Analysis." Journal of Econometrics, 89:339-63.

Kim, J., G.M. Allenby, and P.E. Rossi. 2002. "Modeling Consumer Demand for Variety." Marketing Science 21:229-50.

McAlister, L., and E. Pesemier. 1982. "A Dynamic Attribute-Satiation Model for Choices Made Across Time." Journal of Consumer Research 9:141-50.

McElroy, M. 1977. "Goodness of Fit for Seemingly Unrelated Regressions: Glahn's $R_{v, x}^{2}$ and Hooper' $\bar{r}^{2}$." Journal of Econometrics 6:38187.

McLaughlin, E.W., K. Park, D.J. Perosio, and G.M. Green. 1999. "FreshTracks 1999: The New Dynamics of Produce Buying and Selling." Department of Agricultural, Resource, and Managerial Economics, Cornell University.
Morey, E.R., W.S. Breffle, and P.A. Greene. 2001. "Two Nested Constant-Elasticity-ofSubstitution Models of Recreational Participation and Site Choice: An Alternatives Model and an Expenditures Model." American Journal of Agricultural Economics 83:414-27.

Nevo, A. 2000. "A Practitioner's Guide to Estimation of Random-Coefficients Logit Models of Demand." Journal of Economics and Management Strategy 9:513-48.

Nevo, A. 2001. "Measuring Market Power in the Ready-to-Eat Cereal Industry." Econometrica 69:307-42.

Oren, S., S. Smith, and R. Wilson. 1984. "Pricing a Product Line." Journal of Business 57:S73S100.

Raubitschek, R.S. 1987. “A Model of Product Proliferation with Multiproduct Firms." Journal of Industrial Economics 35:269-79.

Richards, T.J. 2000. “A Discrete/Continuous Model of Fruit Promotion, Advertising and Response Segmentation." Agribusiness: An International Journal. 16:179-96.

Richards, T.J., and P.M. Patterson. 2005a. "Sales Promotion and Cooperative Marketing Strategies among Grocery Retailers." Review of Industrial Organization 26:391-413.

Richards, T.J., and P.M. Patterson. 2005b. "Price Fixity as a Facilitating Mechanism." American Journal of Agricultural Economics 87: 85102.

Roberts, M.J., and L. Samuelson. 1988. "An Empirical Analysis of Dynamic, Non-Price Competition in an Oligopolistic Industry." Rand Journal of Economics 19:200-20.

Slade, M.E. 1995. "Product Rivalry with Multiple Strategic Weapons: An Analysis of Price and Advertising Competition." Journal of Economics and Management Strategy, 4:44576.

Spence, M. 1976. "Product Differentiation and Welfare." American Economic Review 66:407-14.

Sudhir, K. 2001. "Structural Analysis of Manufacturer Pricing in the Presence of a Strategic Retailer." Marketing Science 20:244-64.

United States Department of Labor, Bureau of Labor Statistics. 2004. Employment and Earnings: State and Area. Available at http://stats. bls.gov:80/cgi-bin/dsrv?sa (June 6, 2004).

United States Department of Agriculture. Economic Research Service. 2004. Fruit and Tree Nut Yearbook. Washington DC. June.

United States Department of Agriculture. 1998 and 1999. "Los Angeles Wholesale Fruit and Vegetable Report." Agriculture Marketing Service. Fruit and Vegetable Programs, Market News Branch 84:1-85:248. 
Vaage, K. 2000. "Heating Technology and Energy Use: a Discrete / Continuous Choice Approach to Norwegian Household Energy Demand." Energy Economics 22:649-66.

van Oest, R., R. Paap, and P.H. Franses. 2004. "A Joint Framework for Category Purchase and Consumption Behavior." Working paper, Tinbergen Institute, Erasmus University, Rotterdam, NL.

Villas-Boas, J.M., and R.S. Winer. 1999. "Endogeneity in Brand Choice Models." Management Science 445:1324-38.

Villas-Boas, J.M., and Y. Zhao. 2003. "The Ketchup Marketplace: Retailers, Manufacturers, and Individual Consumers." Working paper, Haas School of Business, University of California at Berkeley, May.

Villas-Boas, S. 2003. "Vertical Contracts Between Manufacturers and Retailers: An Empirical Analysis." Working paper, Department of
Agricultural and Resource Economics, University of California at Berkeley, May.

Vilcassim, N.J., V. Kadiyali, and P.K. Chintagunta. 1999. "Investigating Dynamic Multifirm Market Interactions in Price and Advertising." Management Science 45:499-518,

Walsh, J. 1995. "Flexibility in Consumer Purchasing for Uncertain Future Tastes." Marketing Science 14:148-65.

Walters, R.G., and S.B. McKenzie. 1988. "A Structural Equation Analysis of the Impact of Price Promotions on Store Performance." Journal of Marketing Research 25:5163.

Washington Growers Clearing House. 1998-1999. Annual Report. Wenatchee, WA.

Watson, R. 2004. "Product Variety and Competition in the Retail Market for Eyeglasses." Working paper, Department of Economics, University of Texas at Austin, March. 